\title{
A Technique for Tensile Fatigue and Creep Testing of Fiber-Reinforced Ceramics
}

\author{
JOHN W. HOLMES \\ Ceramic Composites Research Laboratory \\ Dept. of Mechanical Engr. and Applied Mechanics \\ The University of Michigan \\ 2250 G. G. Brown \\ Ann Arbor, MI 48109-2125
}

(Received September 13, 1990)

(Revised December 21, 1990)

\begin{abstract}
An experimental technique for the elevated temperature tensile fatigue and creep testing of fiber-reinforced ceramics is discussed. The experimental approach utilizes edge-loaded specimens with rectangular gage-sections. Novel furnace and grip designs which allow testing in air to $1500^{\circ} \mathrm{C}$ are provided. The specimen, furnace and grip designs discussed in the paper have been successfully used to test unidirectional and cross-ply $\mathrm{SiC}_{\mathrm{f}} / \mathrm{Si}_{3} \mathrm{~N}_{4}, \mathrm{SiC}_{\mathrm{f}} / \mathrm{SiC}, \mathrm{C}_{\mathrm{f}} / \mathrm{SiC}$ and $\mathrm{SiC}_{\mathrm{f}} /$ calcium-aluminosilicate composites.
\end{abstract}

KEY WORDS: tensile, fatigue, creep, ceramic, fiber-reinforced, composites.

\section{INTRODUCTION}

$\mathbf{M}$ ONOLITHIC AND FIBER-REINFORCED ceramics are being considered for a variety of high-temperature structural applications. This has led to the development of various experimental techniques that are suitable for investigating the elevated temperature mechanical behavior of these materials under tensile, compressive and flexural loading histories. For example, cylindrical buttonhead specimens, which are gripped in a collet-type loading fixture, have been successfully utilized to investigate the tensile creep [1-3] and tensile fatigue behavior $[4,5]$ of monolithic ceramics. As discussed by Jenkins et al. [6], a distinct advantage of the buttonhead specimen geometry is the symmetric stress distribution that is obtained by using a cylindrical geometry. Although the buttonhead specimen geometry has been very successful for monolithic ceramics, many of the fiber-reinforced ceramics are obtainable only in the form of flat plates; this constraint dictates the use of a flat specimen geometry. Various face-loaded [7-9], pin-loaded [10-15] and edge-loaded [16-18] specimen geometries have been used for the tensile loading of flat specimens. With face-loading, the specimen ends 
are clamped between flat parallel wedges. Face-loading relies upon friction to transfer the applied load to the test specimen; this requires high gripping forces, which are most often achieved by use of hydraulic loading mechanisms. To provide sufficient surface area for gripping, and to avoid excessive temperatures in the vicinity of the hydraulic grips, the use of long test specimens or water cooling of the grips in the vicinity of the specimen ends is required. Since face-loading relies upon friction for load transfer to the specimen, an increase in specimen thickness requires an increase in the compressive clamping force applied to the specimen ends; this limits the maximum specimen thickness which can be tested without distortion of the specimen or producing specimen fracture in the vicinity of the grips. Pin-loaded specimens typically have one or more circular holes machined into their ends; the applied load is transferred to the specimen through circular loading pins. Prewo et al. [11] and Starrett [12] have used a multiple pinloaded specimen geometry for the elevated temperature mechanical testing of fiber-reinforced ceramics. As noted by Starrett [12], the use of multiple loading pins ensures accurate specimen alignment and allows for a more even distribution of shear loads. In many instances, a simple pin-and-clevis arrangement can be utilized for specimen loading; this straightforward approach has been successfully used for the creep testing of monolithic and whisker reinforced ceramics [13-15]. By using SiC loading pins, the pin-and-clevis arrangement has been used to investigate the creep behavior of ceramics at temperatures up to $1500^{\circ} \mathrm{C}$ [15]. As discussed by Carroll et al. [15], excellent specimen alignment can be achieved with pin-loading. A potential disadvantage of the pin-and-and-clevis arrangement is that the specimen is not rigidly fixed; this could result in specimen rotation about the pin if a nonsymmetric crack distribution develops in the test specimen (this rotation would produce a shift in the centerline of the applied load away from the original specimen axis). Edge-loaded specimens [Figures 1(a) and 1(b)] are machined with tapered ends (typically $5^{\circ}$ to $10^{\circ}$ ) which fit within tapered grip cavities; the applied load is transferred to the specimen along the tapered edges. Since neither pin-loading or edge-loading rely upon friction for transfer of the applied load to the specimen, both of these techniques are suitable for the testing of flat specimens with large cross-sectional areas.

The low failure strain of fiber-reinforced ceramic composites (typically $<1 \%$ ), requires that bending strains be kept to an absolute minimum. Under tensile loading histories, bending strains caused by poor specimen design or misalignment of the loading-train can influence the failure mode and measured stress-strain behavior of brittle matrix composites. The most common source of bending strain is misalignment of the specimen with respect to the centerline of the applied load. At elevated temperatures, a non-symmetric temperature distribution in the specimen or grips can also be a source of bending strains. Of the three experimental approaches discussed above, face-loading presents several challenges with regard to specimen alignment. The most common source of misalignment with faceloaded specimens is inaccurate positioning of the specimen within the grips. In addition, if the face loaded specimens are used with end-tabs (to provide a compliant layer for gripping), unequal thickness of the tabs or the glue-line used to bond the tabs to the specimen can be a source of misalignment. Another potential 
source of misalignment is unequal displacement of the wedges used to grip the specimen (unequal displacements can be caused, for example, by temperature differences within the grips or wear of the mechanisms which force the grip wedges against the specimen faces). These potential sources of misalignment require that each test specimen be instrumented to verify alignment; although accurate, this approach is both time consuming and costly.

The purpose of this paper is to discuss a simple experimental approach which allows use of edge-loaded specimens to study the monotonic tensile, fatigue and creep behavior of fiber-reinforced ceramics at temperatures up to $1500^{\circ} \mathrm{C}$. Since edge-loading does not rely upon friction for load transfer to the specimen, the experimental difficulties (e.g., specimen slippage) typically associated with the testing of high strength composites or specimens with large cross-sectional areas are eliminated. Moreover, the simple gripping technique used with edge-loading allows a high degree of reproducibility in specimen alignment to be achieved. To date, edge-loaded specimens have been successfully used to study the ambient and elevated temperature monotonic strength $[16,17]$, tensile creep $[18,21]$ and tension-tension fatigue $[17,19,20,22]$ of both unidirectional and cross-ply fiberreinforced ceramics.

\section{METHOD FOR ELEVATED TEMPERATURE TESTING}

\section{Specimen Design}

Two edge-loaded specimens designed for ambient and elevated temperature tensile loading of fiber-reinforced ceramics are shown in Figures 1(a) and 1(b). Both specimen designs have an $8^{\circ}$ loading angle and $33 \mathrm{~mm}$ gage length. The primary difference in the two designs is the manner in which a reduction in cross section from the grips to the specimen gage-section is achieved. The first design utilizes two sharp transition radii $(31.75 \mathrm{~mm}$ and $50.8 \mathrm{~mm}$ ) from the grips to the gage-section. The second design, which more closely resembles the geometry used with face loading, utilizes a single $152.4 \mathrm{~mm}$ transition radius. Due to its short length (and hence small grip-to-grip distance), the single reduction specimen is usually suitable only for ambient temperature testing or for hightemperature testing $\left(>1000^{\circ} \mathrm{C}\right)$ with grips machined from a N-base alloy or $\mathrm{SiC}$.

The use of two sharp transition radii in the double blend-radius specimen design allows incorporating a transition zone between the grips and specimen gage-section [labeled $L_{t}$ in Figure 1(a)]. The use of a transition zone allows one to change the specimen gage-length without changing the overall specimen length (for example, increasing $L_{t}$ by $3.5 \mathrm{~mm}$ would increase the gage-section length from 33 to $40 \mathrm{~mm}$ ). Moreover, the transition length $L_{t}$ can be increased, to provide a greater grip-to-grip distance (as discussed later, this approach is sometimes necessary to decrease the temperature gradient developed in the specimen gage-section when water-cooled grips are used). In contrast, for the single blend-radius specimen, the grip-to-grip distance can only be increased by increasing the gage-length or the blend radius. In general, the greater overall length 

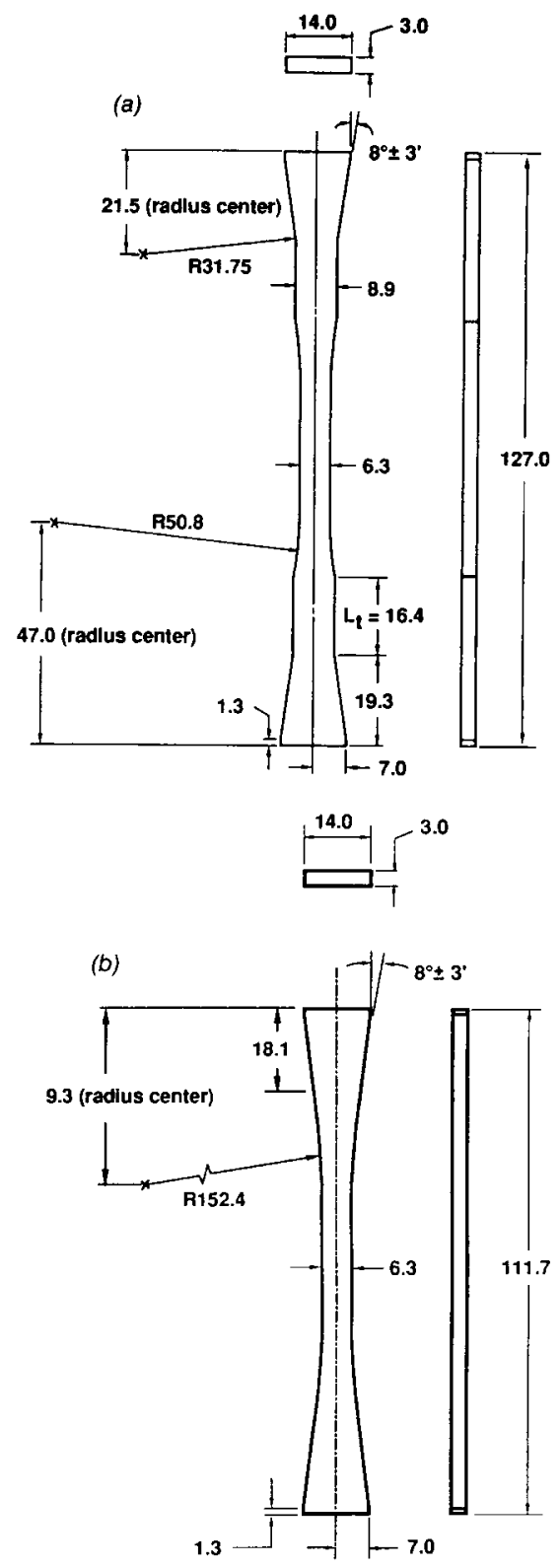

Figure 1. Edge-loaded specimen geometry designed for tensile fatigue and creep testing of ceramic matrix composites. For testing below $1000^{\circ} \mathrm{C}$, shorter double transition-radius specimens, which retain the $33 \mathrm{~mm}$ gage length, can be used (a reduction in specimen length is accomplished by decreasing the transition zone length $L_{t}-$ the transition length can be decreased to $8 \mathrm{~mm}$ without affecting the stress distribution in the gage section [23]). Unless otherwise stated, the tolerance on all dimensions is $\pm 0.03 \mathrm{~mm}$. (a) Double transition-radius specimen and (b) single transition-radius specimen. 


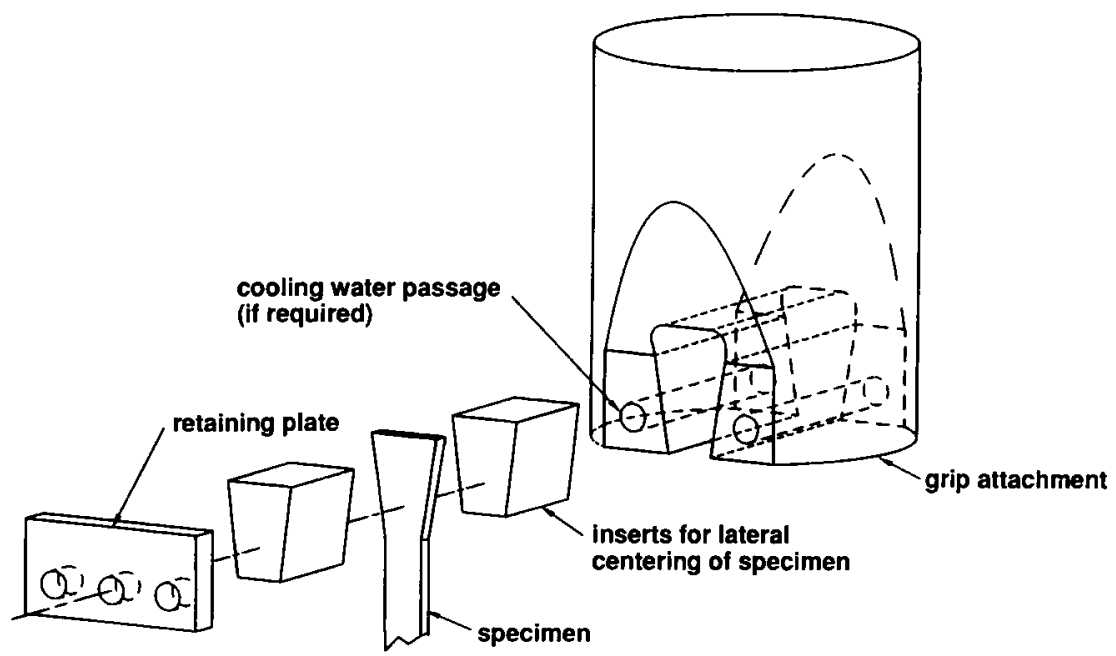

Figure 2. Schematic of grip attachments used for ambient and elevated temperature mechanical testing with edge-loaded specimens. A transverse force applied to one of the grip inserts facilitates specimen removal after testing (a setscrew located in the center of the retaining plates is used to apply the force). With minor modifications, these grip attachments can be adapted to most self-aligning collet grip designs. Detailed drawings for the grip attachments are given in the Appendix.

of the double blend-radius specimen makes it better suited for elevated temperature testing than the single blend-radius specimen.

To reduce material costs, the maximum sample width at the specimen ends was maintained at $14 \mathrm{~mm}$ for both specimen geometries. ${ }^{1}$ To ensure gage-section failures, the gage-section width of $6.3 \mathrm{~mm}$ should not be increased. Note, however, that the specimen thickness can be increased or decreased to accommodate various billet thicknesses (thicknesses ranging from 2 to $20 \mathrm{~mm}$ have been successfully tested). As discussed below, to ensure uniform seating of the specimen within the grips, the $8^{\circ}$ angle at the specimen ends should be machined with a tolerance of at least $1 / 20^{\circ}\left(3^{\prime}\right)$. A tolerance of $1^{\prime}$ to $2^{\prime}$ is preferred.

\section{Grip Attachments}

Simple grip attachments, which were designed for use with the edge-loaded specimens given in Figures 1(a) and 1(b) are shown in Figure 2 (see also the Appendix). These grip attachments, which can be readily mated with self-aligning collet-type grips, can be used with or without water cooling. For a cold-grip arrangement (water cooled) PH 17-4 stainless steel or Inconel 718 provide adequate strength and surface hardness. Although suitable from both strength and hardness considerations, high strength steels were avoided because of the possibility of

'If required, the maximum width at the specimen ends can be reduced to $10 \mathrm{~mm}$ (this requires a reduction in the loading angle to $6^{\circ}$ and a decrease in the gage-section width from $6.3 \mathrm{~mm}$ to $5 \mathrm{~mm}$ ). 
scale or rust formation along the loading surfaces of the grips, which would adversely affect specimen alignment. For the $127 \mathrm{~mm}$ long double blend-radius specimen, uncooled grip attachments machined from the Ni-base superalloy Rene 80 have been used for gage-section temperatures up to $1500^{\circ} \mathrm{C}$ (for the short furnace described in a later section, the grip temperature remains below $750^{\circ} \mathrm{C}$ for gage-section temperatures up to $1500^{\circ} \mathrm{C}$ ). For specimen lengths substantially less than $127 \mathrm{~mm}, \mathrm{SiC}$, machined to the same dimensions as the metallic grips, can be used. Lateral centering of the specimen within the grip attachments is accomplished by use of wedge type inserts machined to fit within the grip cavity (Figure 2). Grip cooling, if required, is accomplished by two water passages machined close to the grip cavity. For water-cooled grips machined from PH 17-4 stainless steel, an inlet water temperature of $20^{\circ} \mathrm{C}$ and cooling water flowrate of $2 \mathrm{~L} / \mathrm{m}$ maintained the surface temperature of the grips below $90^{\circ} \mathrm{C}$ (for gagesection temperatures up to $1500^{\circ} \mathrm{C}$ ).

To prevent wear of the grip cavity (in particular from cross-ply composites which have exposed transverse fibers), the use of $0.1 \mathrm{~mm}$ thick brass between the grip and specimen can be used without adversely affecting specimen alignment. During loading of the specimen, the grips will undergo both axial deformation as well as lateral spreading of the grip ends (note that along the tapered grip face, both axial and transverse forces exist). As a consequence of the lateral elastic displacement of the grip ends, the specimen will become wedged within the grip cavity upon specimen failure or release of the applied load. Thus, to remove the specimen, it is necessary to apply a small transverse force to the specimen ends within the grip cavity (for the grip design presented here this is easily accomplished by removing one of the grip cover plates and using a set screw to apply a transverse force to the specimen-see the Appendix).

\section{Bending Strains Caused by Misalignment}

Assuming accurately machined grip attachments and a properly aligned loadtrain, the most common source of misalignment with edge-loading is inaccurate machining of the angles along the specimen ends. The angles must be symmetric about the specimen centerline. Also, if the angles do not match the angles machined in the grips, specimen failure will occur within the grips. If the specimen angle is less than the corresponding grip angle, the specimen will fail at the contact point where it exits the grip [Figure 3(a)]. Likewise, if the specimen angle is larger than that of the grip, specimen failure will occur near the specimen ends [Figure 3(b)].

To provide an indication of the magnitude of the bending strains which can be expected with edge-loading, the average bending strain present in unidirectional $\mathrm{SiC}_{\mathrm{f}} / \mathrm{Si}_{3} \mathrm{~N}_{4}$ specimens machined to the dimensions and tolerances given in Figure 1(a) was determined. ${ }^{2}$ After alignment of the load-train ${ }^{3}$ (consisting of self-aligning hydraulic grips and the grip attachments described in the Appen-

${ }^{2}$ All measurements discussed in this paper were made on a $100 \mathrm{kN}$ capacity MTS Model 810 servohydraulic test
frame. Similar results have been obtained with a $100 \mathrm{kN}$ capacity Instron Model 1350 servohydraulic.
${ }^{3} \mathrm{~A}$ precision V-block clamped around the cylindrical grip attachments can be used for grip and load-train alignment. 


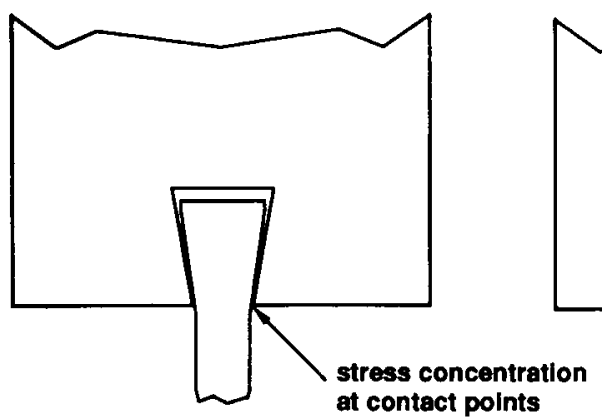

(a)

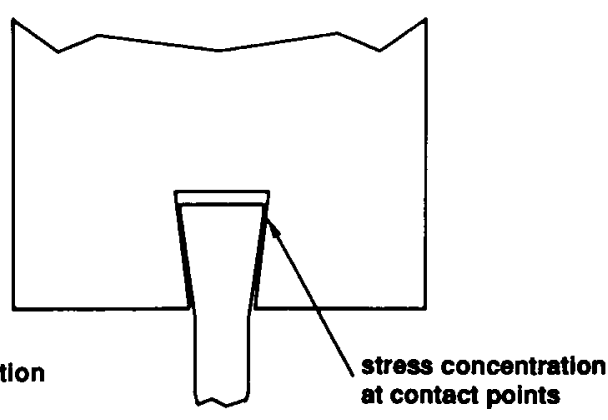

(b)

Figure 3. Potential sources of specimen failure encountered with edge-loaded specimen goometries. (a) Specimen angle < grip angle and (b) specimen angle > grip angle.

dix), the specimen bending strains were measured at room temperature. Although standards do not yet exist for determining bending stresses or the permissible amount of bending during the tensile testing of ceramics, it is common practice $[1,8,17,18]$ to follow the procedure outlined in ASTM Standard E1012-89 [24] for determination of bending strains. Following this standard, strain gages were located on each specimen face; all gages were affixed to the specimen at the same axial position. Bending strains were determined for axial loads between 0.2 and $4 \mathrm{kN}$ (approximately 0.0001 to $0.06 \%$ axial strain). In terms of the four axial strain-gage readings, $e_{1}, e_{2}, e_{3}$ and $e_{4}$, the maximum bending strain $\left(\epsilon_{b}\right)$ is given by [24]

$$
\epsilon_{b}=0.5 \times\left\{\left|e_{1}-e_{3}\right|-\left|e_{2}-e_{4}\right|\right\}
$$

The average axial strain is defined as

$$
\epsilon_{a}=0.25 \times\left(e_{1}+e_{2}+e_{3}+e_{4}\right)
$$

Figure 4(a) shows the maximum bending strain $\left(\epsilon_{b}\right)$ versus average axial strain $\left(\epsilon_{a}\right)$ determined for three identically prepared specimens. Figure 4(b) gives the normalized bending strain $\left(\epsilon_{b} / \epsilon_{a}\right)$ plotted against axial load. For loads above 0.5 $\mathrm{kN}$, the average bending strain was less than $1.5 \%$ of the applied axial strain. The normalized bending strains are comparable to those quoted by others for pinloaded and buttonhead specimen geometries $[4,6,12]$. To determine if the high degree of specimen alignment which was found after initial alignment could be maintained for an extended period without the need for realignment, the bending strains were reevaluated after conducting twenty ambient and elevated temperature tensile tests with $\mathrm{SiC}_{1} / \mathrm{Si}_{3} \mathrm{~N}_{4}$ composites. For experimental consistency, bending strain measurements were made with the same specimens used to determine initial specimen alignment. As shown in Figures 4(a) and 4(b), no significant change in bending strain was observed after conducting the tensile tests. The low variability in bending strain from specimen-to-specimen, and the ability to 
maintain accurate specimen alignment after repeated testing, are considered key advantages of the edge-loading technique.

\section{Furnace Design}

For the $127 \mathrm{~mm}$ double blend-radius specimen given in Figure 1(a), the gripto-grip distance is approximately $88 \mathrm{~mm}$. In view of the limited grip-to-grip clearance, and the need to have a uniform hot-zone to avoid specimen bending strains caused by a non-symmetric temperature distribution, a furnace design based upon induction heating of a $\mathrm{SiC}$ susceptor was chosen. By utilizing a $\mathrm{SiC}$ susceptor, gage-section temperatures up to $1500^{\circ} \mathrm{C}$ in air or inert atmospheres
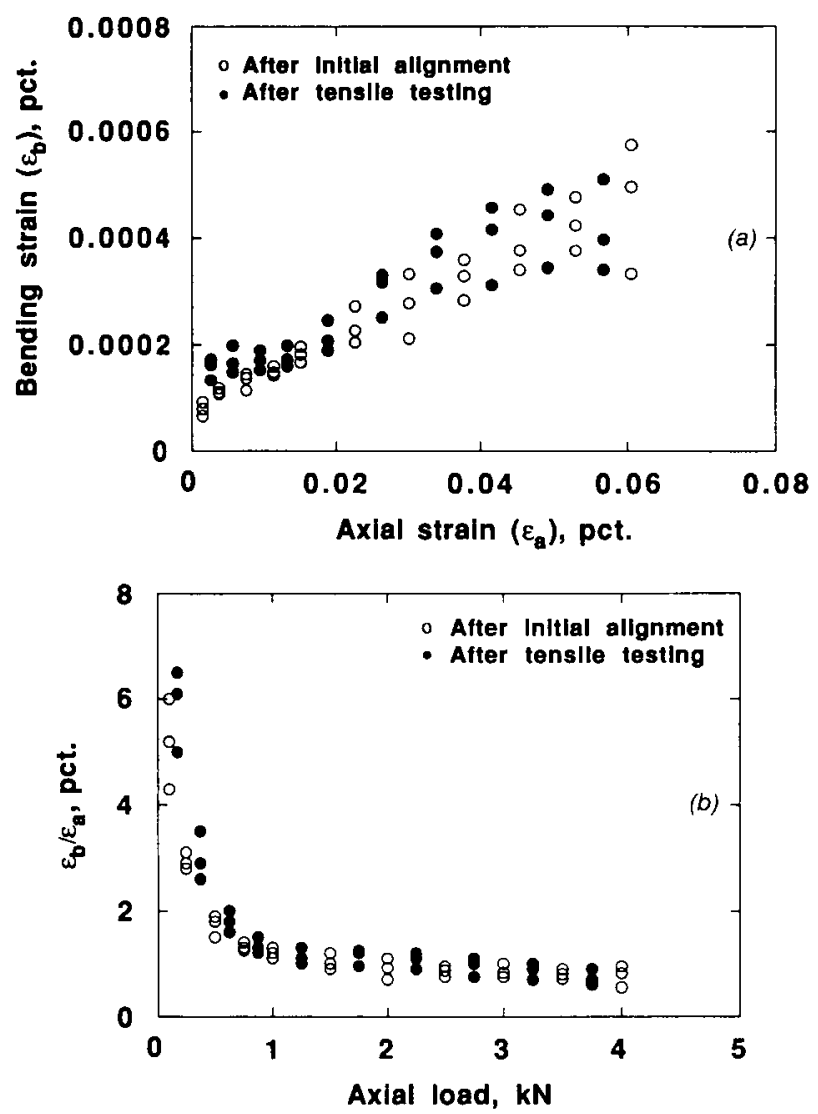

Figure 4. Bending strain measured using $127 \mathrm{~mm}$ long edge-loaded tensile specimens. The data shown were obtained at room temperature, using three unidirectional $\mathrm{SiC}_{1} / \mathrm{Si}_{3} \mathrm{~N}_{4} \mathrm{spec}$ imens machined to the configuration and tolerances given in Figure 1(a). The two sets of data plotted in each figure compare measurements made after initial grip alignment, and after conducting 20 monotonic tensile tests. (a) Bending strain vs. axial strain and (b) normalized bending strain vs. axial bad. 


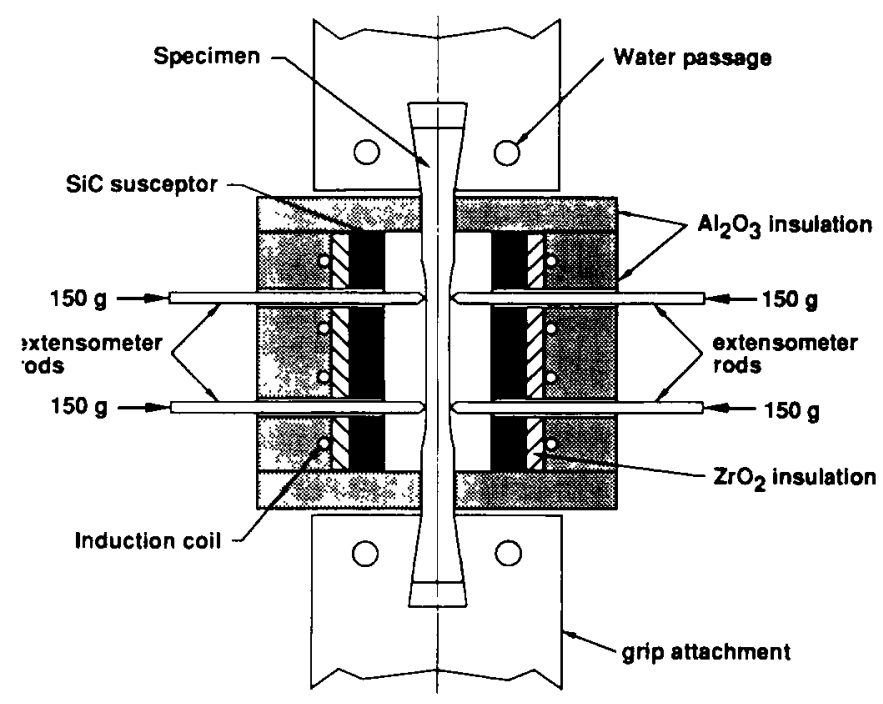

Figure 5. Fumace arrangement used for elevated temperature testing of ceramic matrix composites. A $2.5 \mathrm{~kW}, 450 \mathrm{kHz}$, induction generator provides gage-section temperatures up to $1500^{\circ} \mathrm{C}$ in air.

are readily achieved. A schematic of the furnace, designed for use with the grip attachments described above, is shown in Figure 5. The cylindrical furnace susceptor had an inner cavity diameter of $34 \mathrm{~mm}$ and a wall thickness of approximately $10 \mathrm{~mm}$ (to provide uniform heating of the specimen by radiation from the inner wall of the susceptor, the susceptor must be at least 8 to $10 \mathrm{~mm}$ thick). The induction coil used to heat the susceptor consisted of five turns of $3.2 \mathrm{~mm} \mathrm{di}$ ameter copper tubing (Figure 5). The coil was insulated from the susceptor using approximately $5 \mathrm{~mm}$ of $\mathrm{ZrO}_{2}$ insulation. To minimize heat loss by radiation from the susceptor, the induction coil and susceptor were completely encased in 30 $\mathrm{mm}$ thick $\mathrm{Al}_{2} \mathrm{O}_{3}-\mathrm{SiO}_{2}$ insulation. ${ }^{4}$ Further insulation and structural integrity were achieved by placing the furnace within an $8 \mathrm{~mm}$ thick fibrous $\mathrm{Al}_{2} \mathrm{O}_{3}$ sleeve. The top and bottom furnace covers were constructed from $12 \mathrm{~mm}$ thick fibrous $\mathrm{Al}_{2} \mathrm{O}_{3}$ board. ${ }^{4}$

When using mechanical extensometers and thermocouples/pyrometers for temperature control, clearance holes must be located in the susceptor wall; these holes can be readily machined into a SiC susceptor using standard EDM techniques. To minimize heat loss from the furnace, the diameter of the clearance holes should be as small as possible. For the $3 \mathrm{~mm}$ diameter $\mathrm{Al}_{2} \mathrm{O}_{3}$ or $\mathrm{SiC}$ rods typically used with high temperature extensometers, 4.5 to $5 \mathrm{~mm}$ diameter holes provide sufficient clearance for the testing of fiber-reinforced ceramics. (Note

${ }^{4}$ Zircar Products Inc., Florida. New York: $\mathrm{ZrO}_{2}-$ Type ZYWI5; $\mathrm{Al}_{2} \mathrm{O}_{3}-\mathrm{SiO}_{2}$-Type A Moldable, $\mathrm{Al}_{2} \mathrm{O}_{3}$ Type-AL-30. 
that the strain to failure for most fiber-reinforced ceramics is typically below $1 \%$. For this failure strain, and a $33 \mathrm{~mm}$ gage length, the total displacement of the extensometer rods is under $66 \mu \mathrm{m}$.)

When utilizing high-frequency induction heating, magnetic field fringing can introduce noise into the load cell and extensometer signals. The extent of magnetic field fringing increases as the input power to the furnace is increased. The furnace design discussed in this section requires less than $1.2 \mathrm{~kW}$ of power to achieve specimen temperatures up to $1500^{\circ} \mathrm{C}$; this allowed use of a small $2.5 \mathrm{~kW}$ induction generator for heating of the furnace susceptor ${ }^{5}$ (note that the total power requirement will depend on the amount of magnetic field fringing to the grip attachments - this is a function of the distance from the susceptor to the grip attachments as well as the electrical resistivity and magnetic permeability of the grip material used). Since the $\mathrm{Cu}$ induction coil is in close proximity to the furnace susceptor, the maintenance of adequate cooling water is crucial to prevent failure of the furnace. For temperatures up to $1500^{\circ} \mathrm{C}$, a cooling water flowrate of $0.2 \mathrm{~L} / \mathrm{min}$ provided adequate cooling for the induction coil, and maintained the temperature of the outer furnace wall below $50^{\circ} \mathrm{C}$. Since the furnace is heavily insulated, and the water-cooled induction coil carries away much of the heat which is radiated by the susceptor, the furnace is suitable for long duration inert atmosphere testing within an enclosed chamber [21]. For both air and inert atmospheres, experience with the furnace design described in this section has shown that a furnace life in excess of 8000 hours can be routinely achieved for temperatures of 1200 and $1350^{\circ} \mathrm{C}$ (insufficient data is available to determine furnace life at $1500^{\circ} \mathrm{C}$ ).

With water cooled grip attachments, a large axial temperature gradient exists in the specimen (discussed below). This gradient can be minimized by utilizing a furnace susceptor with a height approximately equal to twice that of the specimen gage-length. The gradient can also be reduced by increasing the overall specimen length. The temperature distribution in a $127 \mathrm{~mm}$ long $\left[0^{\circ} / 90^{\circ}\right]_{4 s}$ $\mathrm{SiC}_{\mathrm{f}} / \mathrm{SiC}$ specimen (45 vol. \% Nicalon fibers, $8 \%$ total porosity content) was measured for central gage-section temperatures of 1200,1350 and $1500^{\circ} \mathrm{C}$. For this purpose, $\mathrm{Pt} / \mathrm{Pt}-10 \% \mathrm{Rh}$ thermocouples were placed at 4 to $8 \mathrm{~mm}$ intervals along the specimen length (the thermocouples were attached using a hightemperature $\mathrm{Al}_{2} \mathrm{O}_{3}$ cement). The axial temperature gradient was determined for both water-cooled grips (PH 17-4 stainless steel) and uncooled grips (Rene 80 ). ${ }^{6}$ The results of these measurements are given in Figures 6(a) and 6(b). With water-cooled grips, the axial temperature gradient in the specimen gage-section ranged from approximately $22^{\circ} \mathrm{C}$ for a central gage-section temperature of $1200^{\circ} \mathrm{C}$, to $16^{\circ} \mathrm{C}$ at $1500^{\circ} \mathrm{C}$. For uncooled grips the axial temperature gradient was reduced to $8^{\circ} \mathrm{C}$ at $1200^{\circ} \mathrm{C}$, and $5^{\circ} \mathrm{C}$ at $1500^{\circ} \mathrm{C}$. Measurement of the temperature on each specimen face showed that the temperature distribution was symmetric; the largest variation in temperature $\left(2^{\circ} \mathrm{C}\right)$ was found with water-cooled grips and a central gage-section temperature of $1200^{\circ} \mathrm{C}$.

\footnotetext{
${ }^{\mathrm{s}}$ Lepel Corporation Model T-2.5-l-KCl-B3W-T induction generator $(2.5 \mathrm{~kW}, 450 \mathrm{KHz})$.

${ }^{\circ}$ Inlet water temperature $=20^{\circ} \mathrm{C}$; flowrate $=2$ liters per minute.
} 


\section{Strain Measurement}

Specimen strains are measured using mechanical extensometers. To minimize the introduction of bending strains in the specimen resulting from transverse loading of the specimen by the extensometer, the extensometer rods should contact the specimen along its edges, rather than the faces (see Figure 5). When the specimen modulus is low (e.g., at elevated temperatures), or where bending strains must be kept to an absolute minimum, the use of two extensometers in a counteracting arrangement can be used (Figure 5). By utilizing two extensometers, the transverse loading force introduced by one extensometer is balanced by equal transverse loading from the opposing extensometer. This simple approach allows utilization of a moderate extensometer contact force (e.g., 100 to $200 \mathrm{~g}$ per rod) without introducing a net bending moment in the specimen (as dis-

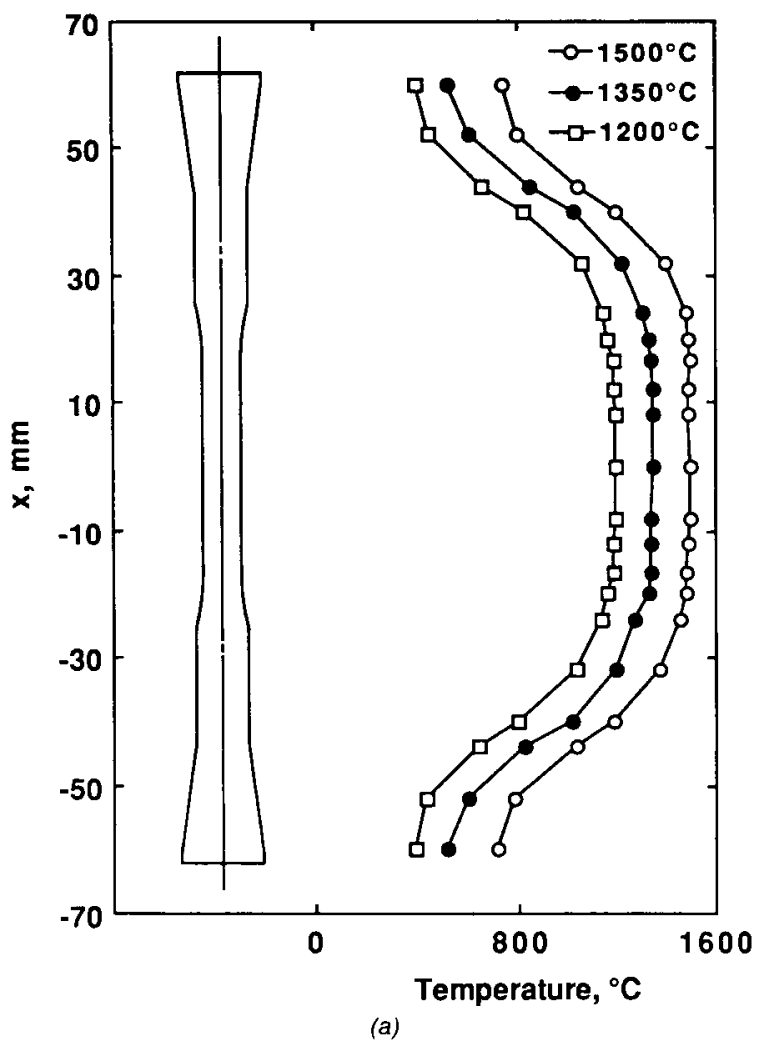

Figure 6. Axial temperature distribution in a $127 \mathrm{~mm}$ long $\left[0^{\circ} / 90\right]_{4 \mathrm{~S}} \mathrm{SiC} / \mathrm{SiC}$ specimen for central gage-section temperatures of 1200,1350 and $1500^{\circ} \mathrm{C}$. The data shown were obtained using $1.0 \mathrm{~mm}$ dia. $\times 0.2 \mathrm{~mm}$ thick thermocouple junctions which were bonded to the specimen surface with $\mathrm{Al}_{2} \mathrm{O}_{3}$ cement. (a) Water-cooled grips ( $\mathrm{PH} 17.4$ stainless steel) and (b) uncooled grips (Rene 80). 


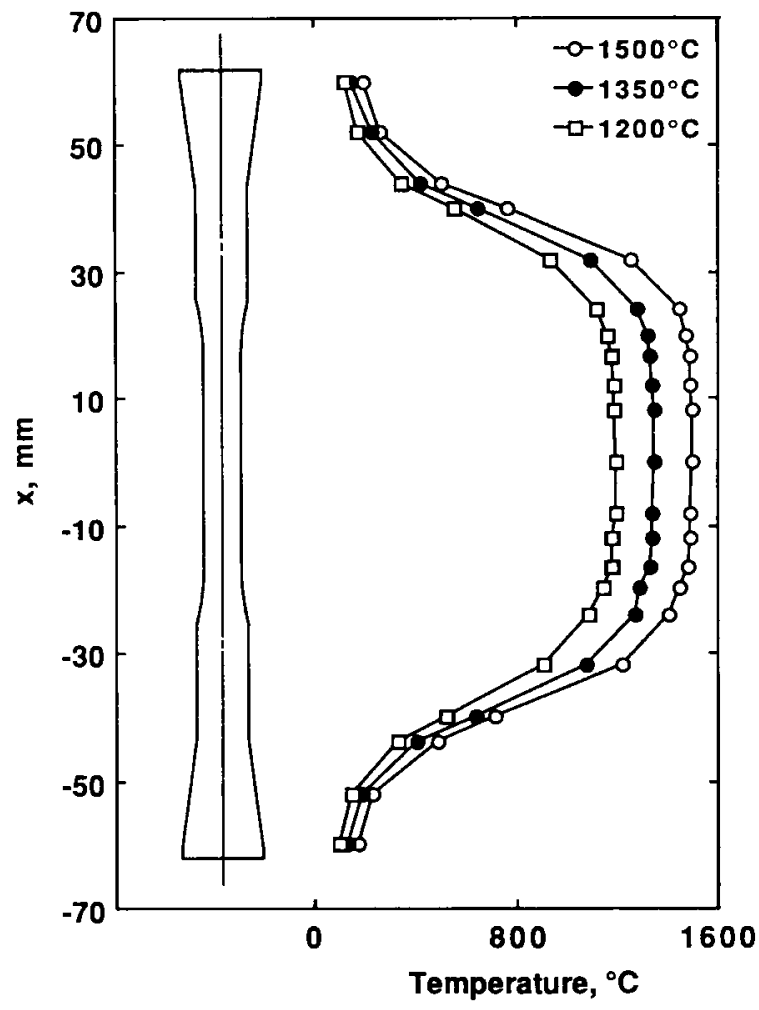

(b)

Figure 6 (continued). Axial temperature distribution in a $127 \mathrm{~mm}$ long $\left.10^{\circ} / 90\right]_{4 S} \mathrm{SiC} / \mathrm{SiC}$ specimen for central gage-section temperatures of 1200,1350 and $1500^{\circ} \mathrm{C}$. The data shown were obtained using $1.0 \mathrm{~mm}$ dia. $\times 0.2 \mathrm{~mm}$ thick thermocouple junctions which were bonded to the specimen surface with $\mathrm{Al}_{2} \mathrm{O}_{3}$ cement. (a) Water-cooled grips ( $\mathrm{PH} 17.4$ stainless steel) and (b) uncooled grips (Rene 80 ).

cussed below, a moderate contact force is sometimes required to prevent extensometer slip during specimen fracture or high frequency fatigue testing).

For temperatures up to $1200^{\circ} \mathrm{C}$, large grain, high-purity $\mathrm{Al}_{2} \mathrm{O}_{3}$ rods have proven satisfactory for long duration creep or fatigue testing $(-1000 \mathrm{~h})$. At higher temperatures, $\mathrm{SiC}$ rods should be used to minimize possible errors associated with creep deformation of the extensometer rods. Expansion and contraction of the extensometer rods, caused by small changes in furnace temperature $\left(\approx 3^{\circ} \mathrm{C}\right)$ can produce fluctuations in the strain readings. Moreover, since the extensometer rods extend outside the furnace, changes in the ambient temperature near the furnace will cause expansion and contraction of the portion of the extensometer rods which are external to the furnace. To avoid strain fluctuations, the 
furnace temperature should be controlled to within $\pm 1^{\circ} \mathrm{C}$, and the temperature in the vicinity of the experimental setup to within $\pm 1^{\circ} \mathrm{C}$.

When testing fiber-reinforced ceramics, the energy expended during matrix or fiber fracture releases considerable energy, which can cause slippage of the extensometer rods. Slippage can also occur during fatigue testing, in particular at frequencies above $10 \mathrm{~Hz}$. To prevent slippage, it was sometimes necessary to machine shallow conical depressions $\left(120^{\circ}\right.$ included angle, $<200 \mu \mathrm{m}$ deep) into the edge of the test specimens; the tips of the extensometer rods were machined with an included angle of approximately $100^{\circ}$. For $0^{\circ}$ and $0^{\circ} / 90^{\circ} \mathrm{SiC}_{\mathrm{f}} / \mathrm{Si}_{3} \mathrm{~N}_{4}$ and $\mathrm{SiC}_{\mathrm{f}} / \mathrm{CAS}$ composites, the presence of $200 \mu \mathrm{m}$ deep dimples did not influence specimen failure. However, similar dimples occasionally served as the initiation site for failure of $0^{\circ} / 90^{\circ} \mathrm{C}_{\mathrm{f}} / \mathrm{SiC}$ composites; for this composite system, machining dimples into small pads, formed along the specimen edge using an $\mathrm{Al}_{2} \mathrm{O}_{3}$ cement, was found to be a useful technique for preventing failures associated with direct dimpling of the test specimen. This technique has been used successfully at temperatures up to $1200^{\circ} \mathrm{C} .{ }^{8}$ In addition to locating the tips of the extensometer rods in conical dimples, the use of a moderate extensometer loading rod force $(>100 \mathrm{~g})$ was found useful for preventing extensometer slip during fatigue at frequencies of $10 \mathrm{~Hz}$ and above.

As an indication of the capabilities of the experimental technique described in this paper, recent experimental results obtained from long duration tensile creep and tension-tension fatigue testing of fiber-reinforced $\mathrm{SiC}_{\mathrm{f}} / \mathrm{Si}_{3} \mathrm{~N}_{4}$ composites are given in Figures 7 and 8 . The creep tests were conducted in air at $1350^{\circ} \mathrm{C}$, for times in excess of $800 \mathrm{~h}$. The high cycle fatigue tests, which investigated the influence of stress ratio $\left(\sigma_{\min } / \sigma_{\max }\right)$ on high cycle fatigue life $\left(\sim 5 \times 10^{6}\right.$ cycles $)$, were conducted at $1200^{\circ} \mathrm{C}$ and a sirussoidal frequency of $10 \mathrm{~Hz}$. Both the single and double blend-radius specimens presented in this paper have provided consistent gage-section failures during monotonic tension, creep and fatigue testing of fiber-reinforced ceramics of varying strengths and fiber architecture (see Figures 9(a)-9(c).

\section{SUMMARY}

The use of edge-loaded specimens for the ambient and elevated temperature creep and fatigue testing of fiber-reinforced ceramics offers a viable alternative to the use of face or pin-loaded specimen geometries. A distinct advantage of using edge-loading is the ease in which highly accurate specimen alignment can be maintained and the ability to test specimens of large cross section. The simple

\footnotetext{
${ }^{7}$ An LFE Model 2010 setpoint controller was used to control furnace temperature. For long duration testing below $1400^{\circ} \mathrm{C}$, Type $\mathrm{S}(\mathrm{Pt} / \mathrm{Pt}-10 \% \mathrm{Rh})$ or Type $\mathrm{B}(\mathrm{Pt} / \mathrm{Pt}-6 \% \mathrm{Rh})$ thermocouples were used to determine specimen temperature and provide feedback to the temperature controller (the thermocouples contacted the specimen at the center of the gage-section. For long duration testing at temperatures in excess of $1400^{\circ} \mathrm{C}$, either Type B thermocouples or a two-color optical pyrometer (Micron Inc. Model M78) were utilized.

${ }^{8}$ An alternative approach is to use chisel-end rods which are lightly bonded to the specimen edge with ceramic cement.
} 


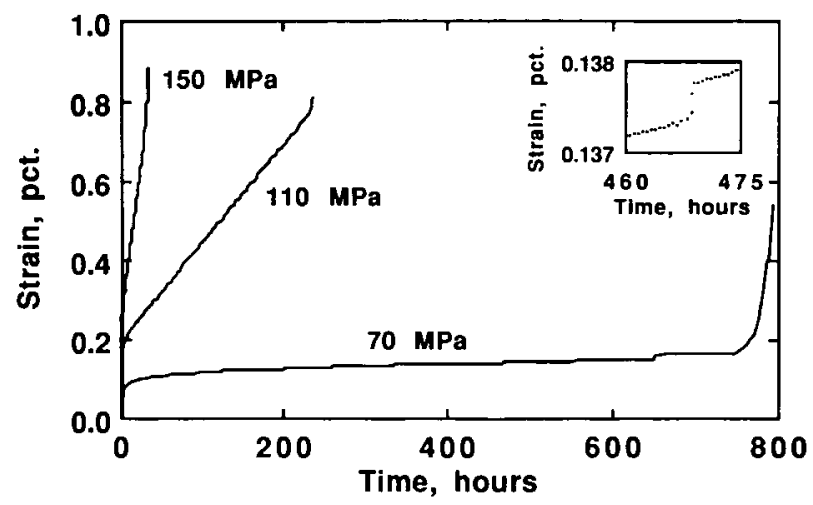

Figure 7. Tensile creep behavior of hot-pressed unidirectional $\mathrm{SiC}_{f} / \mathrm{Si}_{3} \mathrm{~N}_{4}$ composite determined using the experimental approach described in this paper. The discontinuous strain jumps shown in the inset are attributed to fiber/matrix fracture during long duration creep at 70 and $110 \mathrm{MPa}$. Extensometer and load cell signals were gathered at 16-bit resolution. From Holmes [18].
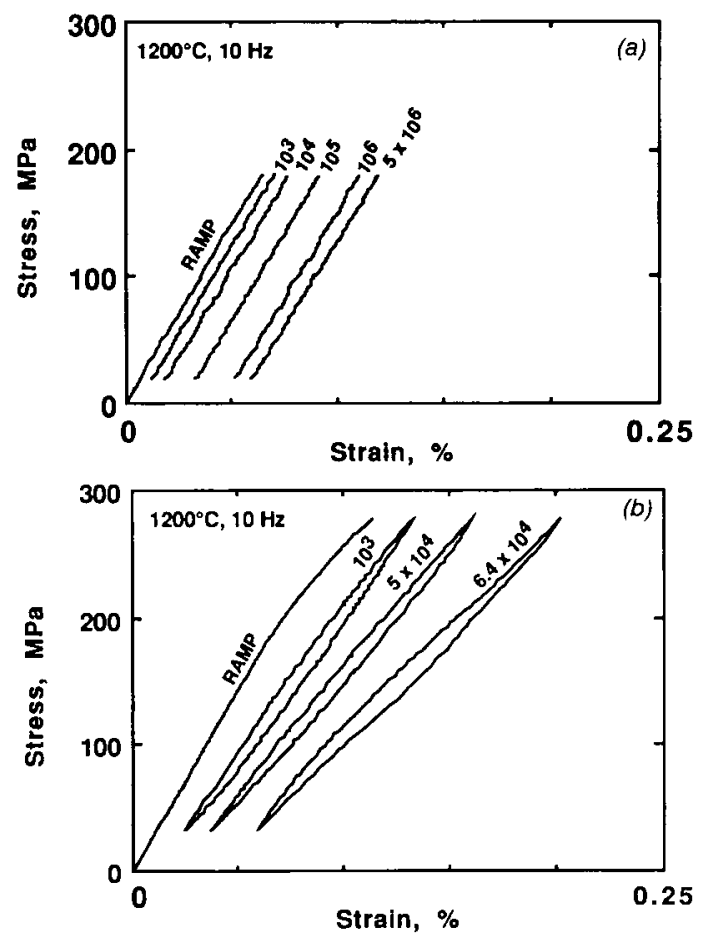

Figure 8. Cyclic stress-strain behavior of a unidirectional $\mathrm{SiC}_{1} / \mathrm{Si}_{3} \mathrm{~N}_{4}$ composite determined using the experimental approach discussed in this paper. Extensometer and load cell signals were gathered at 16-bit resolution. The numbers above each curve correspond to accumulated fatigue cycles. From Holmes [19]. (a) $\sigma_{\max }=180 \mathrm{MPa}, N_{t}>5 \times 10^{6}$ cycles and (b) $\sigma_{\max }=270 \mathrm{MPa}, N_{f}=6.5 \times 10^{4}$ cycles. 


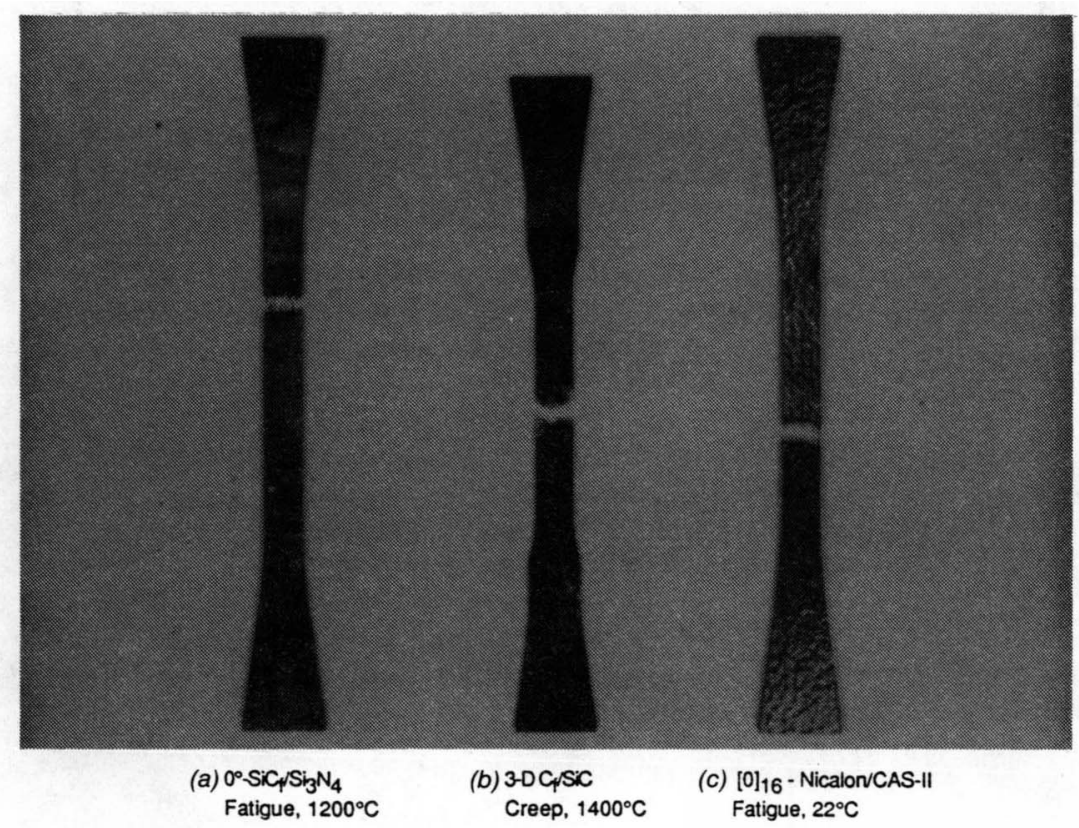

Figure 9. Representative gage-section failures obtained for specimens of varying strength and fiber architecture. To accommodate smaller billets, the double transition-radius specimen in Figure $9(b)$ was machined with a smaller transition length $\left(L_{1}\right)$ than that shown in Figure 1(a). The single transition-radius specimen in Figure $9(\mathrm{c})$ was machined to the dimensions given in Figure $1(\mathrm{~b})$. (a) $0^{\circ} \mathrm{SiC}_{f} / \mathrm{Si}_{3} \mathrm{~N}_{4}$; fatigue, $1200^{\circ} \mathrm{C}$, (b) $3-\mathrm{D} \mathrm{C} / \mathrm{SiC}$; creep, $1400^{\circ} \mathrm{C}$ and (c) $[0]_{16}$-Nicalon/CAS. 11 ; fatigue, $22^{\circ} \mathrm{C}$.

grip and furnace designs presented in this paper allow tensile creep and tensiontension fatigue testing in air or inert atmospheres, at temperatures up to $1500^{\circ} \mathrm{C}$. Moreover, the grip attachments can be readily adapted for use with self-aligning collet-type grips. To date, the specimen and grip designs presented in this paper have been successfully used to investigate the creep and fatigue behavior of $\mathrm{SiC}_{1} / \mathrm{Si}_{3} \mathrm{~N}_{4}, \mathrm{SiC}_{1} / \mathrm{CAS}, \mathrm{SiC}_{1} / \mathrm{SiC}$ and $\mathrm{C}_{1} / \mathrm{SiC}$ composites.

\section{APPENDIX}

\section{Grip Attachments for Use with Edge-Loaded Specimen Geometries}

Detailed drawings of grip attachments designed for use with the edge-loaded specimen geometries discussed in the text [see Figures 1(a) and 1(b)] are given in Figures $\mathrm{Al}(\mathrm{a})-\mathrm{Al}(\mathrm{d})$. $\mathrm{PH} \mathrm{17-4}$ stainless steel or Inconel 718 are suitable for use with water-cooled grip attachments. Uncooled grip attachments of similar geometry and dimensions can be machined from Rene 80 or SiC. 


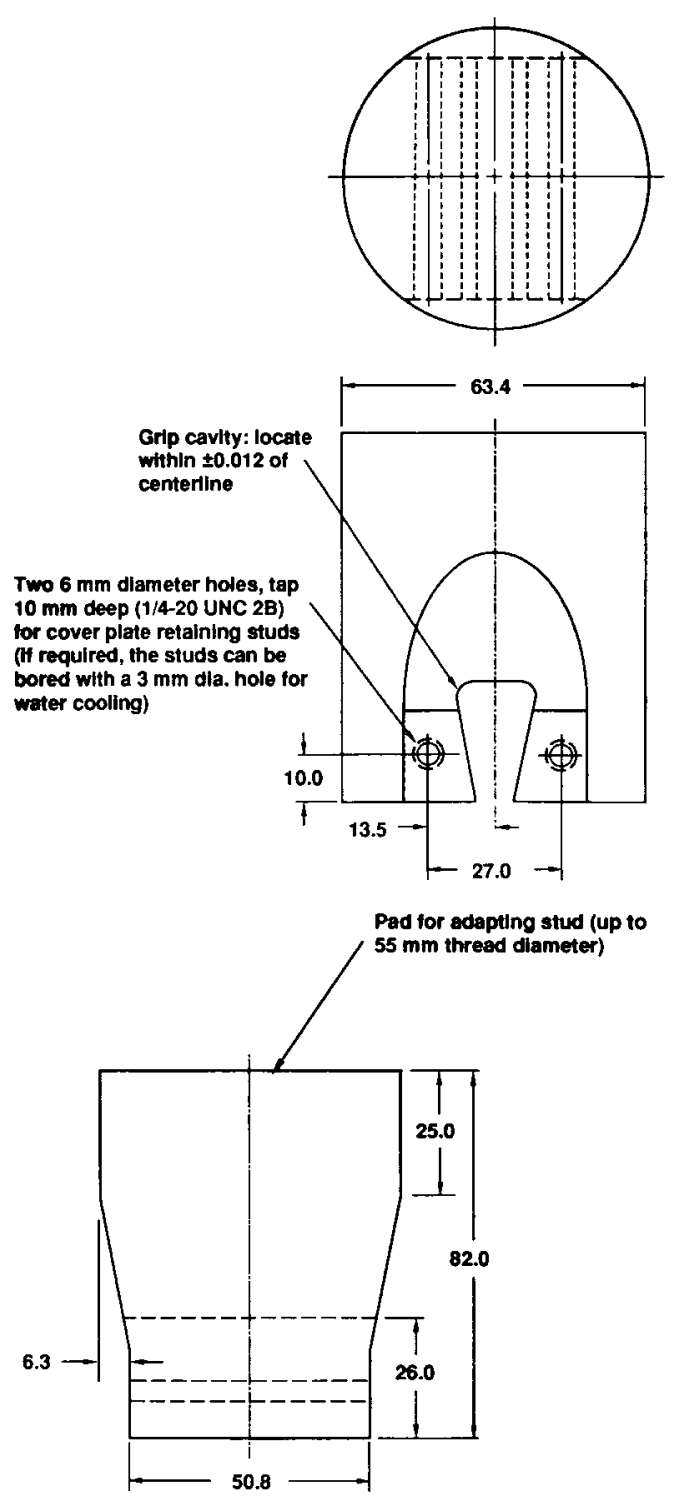

(a)

Figure A1. Grip attachments for use with edge-loaded tensile specimens machined with an $8^{\circ}$ loading angle. Unless otherwise stated, the tolerance on all dimensions is $\pm 0.1 \mathrm{~mm}$. (a) Grip attachment, (b) detail drawing of grip cavity, (c) grip cover-plates and (d) grip inserts. 


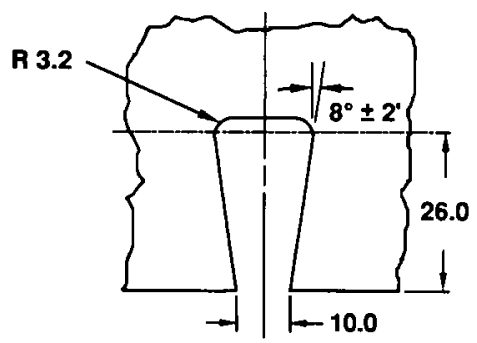

(b)

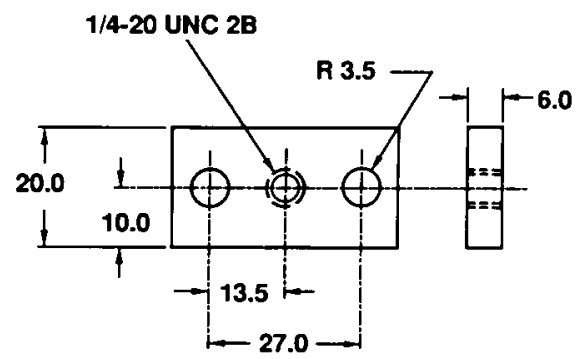

(c)

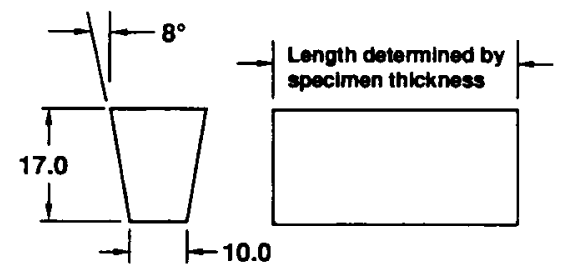

(d)

Figure A1 (continued). Grip attachments for use with edge-loaded tensile specimens machined with an $8^{\circ}$ loading angle. Unless otherwise stated, the tolerance on all dimensions is $\pm 0.1 \mathrm{~mm}$. (a) Grip attachment, (b) detail drawing of grip cavity, (c) grip cover-plates and (d) grip inserts. 


\section{REFERENCES}

1. Ferber, M. K., M. G. Jenkins and V. J. Tennery. 1990. Ceram. Eng. Sci. Proc., 11(7-8): 1028-1045.

2. Chuck, L., S. M. Goodrich and N. L. Hecht. 1990. Ceram. Eng. Sci. Proc., 11(7-8):1007-1027.

3. Kossowsky, R. K., D. G. Miller and E. S. Diaz. 1975. J. Mater. Sci., 10:983-997.

4. Liu, K. C. and C. R. Brinkman. 1986. Proceedings of the Twenty-Third Automotive Technology Development Contractors' Coordination Meeting, Dearborn, Michigan, October 21-24, 1985. Warrendale PA: SAE, pp. 279-284.

5. Masuda, M., T. Soma, M. Matsui and I. Oda. 1988. Ceram. Eng. Sci. Proc., 9(9-10): $1371-1382$

6. Jenkins, M. G., M. K. Ferber and R. L. Martin. 1990. Ceram. Eng. Sci. Proc., 11(9-10): 1346-2363.

7. Rousseau, C. Q. 1990. "Monotonic and Cyclic Behavior of a Silicon Carbide/CalciumAluminosilicate Ceramic Composite," Thermal and Mechanical Behavior of Metal Matrix and Ceramic Matrix Composites, ASTM STP 1080, J. M. Kennedy, H. H. Moeller and W. S. Johnson, eds., Philadelphia, PA: American Society for Testing and Materials.

8. Zawada, L. P., L. M. Butkus and G. A. Hartman. 1990. Ceram. Eng. Sci. Proc., 11(9-10): $1592-1606$.

9. Mah, T., M. G. Mendiratta, A. P. Katz, R. Ruh and K. S. Mazdiyasni. 1985. J. Am. Ceram. Soc., 68(9):C248-C251.

10. Prewo, K. M. 1987. J. Mater. Sci., 22:2695-2701.

11. Nardone, V. C. and K. M. Prewo. 1988. J. Mater. Sci., 23(1):168-180.

12. Starrett, S. 1990. Ceram. Eng. Sci. Proc., 11(9-10):1281-1294.

13. Wakai, F., S. Sakaguchi, Y. Matsuno and H. Okuda. 1986. "Tensile Creep of Hot-Pressed $\mathrm{Si}_{3} \mathrm{~N}_{4}$," in Ceramic Components for Engines, S. Somina, E. Kanai and K. Ando, eds., New York: Elsevier Applied Science Publishers, pp. 279-285.

14. Wiederhom, S. M., D. E. Roberts, T-J Chuang and L. Chuck. 1988. J. Am. Ceram. Soc., 71(7):602-608.

15. Carroll, D. F., S. M. Wiederhorn and D. E. Roberts. 1989. J. Am. Ceram. Soc., 68(9):1610-1614.

16. Mandell, J. F., D. H. Grande and J. Jacobs. 1987. J. Engr. Gas Turbines and Power, 109:267-273.

17. Holmes, J. W., T. Kotil and W. T. Foulds. 1989. "High Temperature Fatigue of SiC FiberReinforced $\mathrm{Si}_{3} \mathrm{~N}_{4}$ Ceramic Composites," in Symposium on High Temperature Composites, American Society for Composites, Lancaster, PA: Technomic Publishing Co., Inc., pp. 176-182.

18. Holmes, J. W. 1990. "Tensile Creep Behavior of a Hot-Pressed SiC Fiber-Reinforced $\mathbf{S i}_{3} \mathbf{N}_{4}$ Composite," J. Mater. Sci., 26:1801-1814.

19. Holmes, J. W. "Influence of Stress-Ratio on the Elevated Temperature Fatigue of a SiC FiberReinforced $\mathrm{Si}_{3} \mathrm{~N}_{4}$ Composite," J. Am. Ceram. Soc., 74(7):1639-1645.

20. Schuler, S. F. and J. W. Holmes. "Influence of Frequency of the Fatigue Life of a C-Fiber SiCMatrix Composite," submitted to J. Am. Ceram. Soc.

21. Holmes, J. W. and J. Morris. “Tensile Creep of a 3-D C-Fiber SiC-Matrix Composite," presented at the 15th Annual Conference on Composites and Advanced Ceramics, Cocoa Beach, FL, January 13-16, 1991 .

22. Holmes, J. W. and S. F. Shuler. 1990. J. Mater. Sci. Lett., 9:1290-1291.

23. Holmes, J. W. "Stress Analysis of an Edge-Loaded Ceramic Tensile Specimen," in preparation.

24. 1989. ASTM Annual Book of Standards, Vol. 3.01. Philadelphia, PA: American Society for Testing and Materials. 